\title{
SIMULATION OF STRUCTURE, TRACK AND LANDFALL OF TROPICAL CYCLONE BIJLI USING WRF-ARW MODEL
}

\author{
K. M. ZAHIR RAYHUN, D. A. QUADIR ${ }^{1}$, M. A. MANNAN CHOWDHURY, \\ M. N. AHASAN ${ }^{2}$ AND M.S. HAQUE
}

Jahangirnagar University, Savar, Dhaka, Bangladesh

\begin{abstract}
An attempt was made to simulate the structure, track, landfall and a few dynamical aspects of the tropical cyclone Bijli that formed over the Bay of Bengal using WRF-ARW model. WRF model was run in a single domain using KF cumulus parameterization schemes with WSM 3 micro physics and YSU planetary boundary layer scheme. The ARW model was run for 24, 48, 72 and 96 hrs to simulate structure, track and landfall of tropical cyclones Bijli. The different simulated parameters viz. minimum sea level pressure, maximum wind speed, convective available potential energy and relative vorticity have been studied. The results showed that the model is capable to forecast the formation of the first depression $60-78 \mathrm{hrs}$ in advance. This indicates the high and unique predictive power of ARW model for predicting the tropical cyclone formation. The model generates a realistic structure of the tropical cyclones with high spatial details. This was possible due to the higher spatial resolution of the regional model. One of the outstanding findings of the study is that the model was successfully predicted the tracks, recurvature and probable areas and time of landfall of the selected tropical cyclone Bijli with high accuracy even in the $96 \mathrm{hrs}$ predictions.
\end{abstract}

Key words: Tropical cyclone, Vorticity, Divergence, Vertical wind shear, Bay of Bengal

\section{INTRODUCTION}

The tropical cyclones (TCs) over the Bay of Bengal $(\mathrm{BoB})$ form primarily in premonsoon season (March - May) and post-monsoon season (October - December) unlike in the other ocean basins which occur around late summer to early fall. During this period, the monsoon trough is located sufficiently over the open water of the Indian seas which trigger low pressure system and its development into a mature cyclone (Lee et al. 1989). The geographical structure of the BoB including shallow bathymetry, many river basins, poor socio-economic conditions and large population density along the east coast of India enhances the damage and loss of lives and properties due to TCs. Mohanty and Gupta (1997), Gupta (2006) discussed the limitations of statistical methods beyond 24

\footnotetext{
${ }^{1}$ Uttara University, Mirpur, Dhaka, Bangladesh.

${ }^{2}$ SAARC Meteorological Research Centre (SMRC), Dhaka, Bangladesh.

${ }^{3}$ Govt. Ashek Mahmud College, Jamalpur, Bangladesh.
} 
hours. However, high resolution mesoscale models could provide better guidance for TC forecast up to 72 hours. Pattanayak and Mohanty (2008) made a comparative study on the performance of both mesoscale model version 5 (MM5) and Advanced Research Weather Research Forecasting (ARW) models in the simulation of tropical cyclones over Indian seas and demonstrated the superiority of the ARW model over MM5. ARW model is used extensively worldwide for the simulation of various weather events, such as heavy rainfall (Mohanty et al. 2011, Hong and Lee 2009), monsoon depressions (Routray et al. 2010) and tropical cyclones (Osuri et al. 2012, Pattanaik and Ramarao 2009, Davis et al. 2008). The model is also used to study the land surface processes (Niyogi et al. 2006). The performance of high resolution mesoscale models highly depends on the quality of initial conditions. Moreover, the initial and boundary conditions for these models are derived from the global model analyses and forecast fields which are relatively coarser in resolution. Because of lack of sufficient conventional observations over the oceans where TCs form and evolve, the global analyses are ill-defined in representing the initial structure and position of the vortex. According to Mohanty et al. (2010), the initial vortex position error in global analyses is about $80-100 \mathrm{~km}$ and further contributes to more track forecast errors. The primary and important task is to reduce the errors in initial conditions. The quality of initial conditions can be improved with the mesoscale data assimilation of high dense observations. Several previous studies have demonstrated that the assimilation of sea surface and upper air satellite-derived winds near and around the centre of the storm can substantially improve the initial analyses of TCs and hence the prediction of track, intensity and structure (Velden et al. 1998, Chen 2007, Pu et al. 2008, Osuri et al. 2012b).

In the present study, the comprehensive performance of WRF modeling system in structure, track and landfall prediction of a selected tropical cyclone Bijli over the Bay of Bengal is presented.

A convective cloud cluster developed over southeast Bay of Bengal and adjoining Andaman sea on 10 April, 2009. It persisted over the same region till 13 April, 2009 under its influence, a low pressure area formed over southeast Bay of Bengal on 13 April, 2009. It became a well marked low pressure area over the southeast and adjoining central Bay of Bengal at 0300 UTC of 14 April, 2009 with associated cyclonic circulation extending up to mid-tropospheric level. The well marked low pressure area concentrated into a depression and lay centred near lat. $12.5 \mathrm{ON}$ and long. 88.50E at $0900 \mathrm{UTC}$ of 14 April over southeast and adjoining central Bay of Bengal. It further intensified into a deep depression and lay centred over central and adjoining southeast Bay of Bengal near lat. 14.00N and long. 87.50E at $0600 \mathrm{UTC}$ of 15 April, 2009. It intensified into a cyclonic storm Bijli and lay centred at 1200 UTC of 15 April over central and adjoining southeast Bay of Bengal near lat. $15^{\circ} \mathrm{N}$ and lon. $86.50^{\circ} \mathrm{E}$. The system moved in a north- 
northwesterly direction till 0900 UTC of 16 April and recurved thereafter towards northnortheast. The system moved northeastwards skirting the coast (it was lying around 100 km from Orissa coast at 0000 UTC of 17 April) from 17 April morning onwards, the system interacted with land surface also. As a result the system gradually weakened into a deep depression at 0900 UTC and into a depression at 1200 UTC of 17 April near at Bangladesh coast.

\section{MODEL EXPERIMENTAL SETUP, DATA USED}

To simulate a selected tropical cyclone Bijli a domain of dimension $10-30^{\circ} \mathrm{N}$ and 80 $100^{\circ} \mathrm{E}$ was selected to cover the Bay of Bengal basin at $24 \mathrm{~km}$ horizontal resolution with 21 vertical sigma levels. Fig. 1 shows the horizontal domain of the model. The model domain consists of $93 \times 99$ grid points. Marcator map projection has been used.

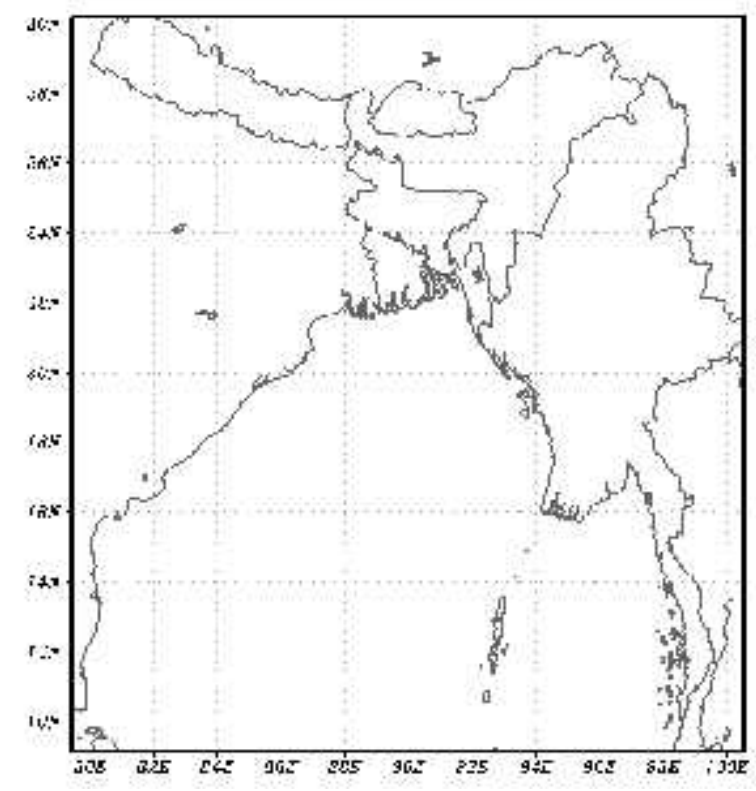

Fig. 1. WRF model domain setup.

Table 1. Selected parameterization schemes of different physics options.

\begin{tabular}{ll}
\hline Physics option & Selected parameterization schemes \\
\hline Microphysics & WRF-single moment 3-class (WSM3) \\
Cumulus parameterizations & Kain-Fritch (KF) cumulus parameterization \\
Surface layer physics & Monin-Obukhov with Carslon-Bolan viscous sub-layer option \\
Land surface model & Noah 4-layer Land Surface Model (LSM) \\
Planetary boundary layer physics & Yonsei University scheme \\
Long wave radiation physics & Rapid Radiative Transfer Model (RRTM) \\
Short wave radiation physics & Dudhia schemes \\
\hline
\end{tabular}


The United States Geological Survey (USGS) terrain data at $30 \mathrm{sec}$ interval were used to simulate the topographical features and land use/vegetation fields. The National Centre for Environment Prediction (NCEP) Final Reanalysis (FNL) data $\left(1^{\circ} \times 1^{\circ}\right.$ resolution) was utilized as initial and lateral boundary conditions (LBCs) which are updated at six hourly intervals. The model results are compared with the IMD best track data to demonstrate the performance of the model.

\section{METHODOLOGY}

The ARW model was run for 24, 48, 72 and 96 hrs to simulate structure, track and landfall of tropical cyclones Bijli formed in the Bay of Bengal. The model was initialized with 0000, 0600, 1200 and 1800 UTC initial and boundary field from NCEP FNL. The model results are presented in the graphical and tabular forms and compared with the IMD best track data to demonstrate the performance of the modelling exercise.

The discussion in this section is mainly on the structure, track and landfall of selected tropical cyclone in terms of different parameters viz. minimum sea level pressure (MSLP), maximum wind speed (MWS), convective available potential energy (CAPE) and relative vorticity $(\zeta)$. These parameters are directly related to the intensity of tropical disturbances.

The distribution of model simulated surface pressure, winds, relative vorticity, temperature field, moisture fields and convective available potential energy were investigated for understanding the horizontal and vertical structure of the selected disturbances at their highest maturity stage.To study the tracks and landfall of the selected cyclonic systems the model was run for 24, 48, 72 and $96 \mathrm{hrs}$ before the landfall time.

\section{RESULTS AND DISCUSSION}

The horizontal distribution of mean sea level pressure (MSLP) for the cyclone Bijli at its mature stage according to the model simulation at 0000 UTC of 18 April, 2009 has been shown in Fig. 2a. The Figure shows that the isobar has near circular arrangement around the cyclone centre. The contour interval is $1 \mathrm{hPa}$. Considering the outermost closed isobar, the system's horizontal size is estimated as 2 lon. $(220 \mathrm{~km})$ in the east-west direction and 2 lat. $(220 \mathrm{~km})$ in the north-south demonstrating some asymmetry of its circular shape in its horizontal structure having slight elongation in the east-west direction. Figure shows that the system is a strong one and it has organized core with pressure gradient.

The distribution of the sea level pressure of the cyclone Bijli along east-west section passing through its centre $\left(18.9^{\circ} \mathrm{N}, 90^{\circ} \mathrm{E}\right)$ has been shown in Fig. 2b. The figure 
demonstrates that there is a strong pressure gradient. Model simulated system shows that the MSLP is of around $989 \mathrm{hPa}$.
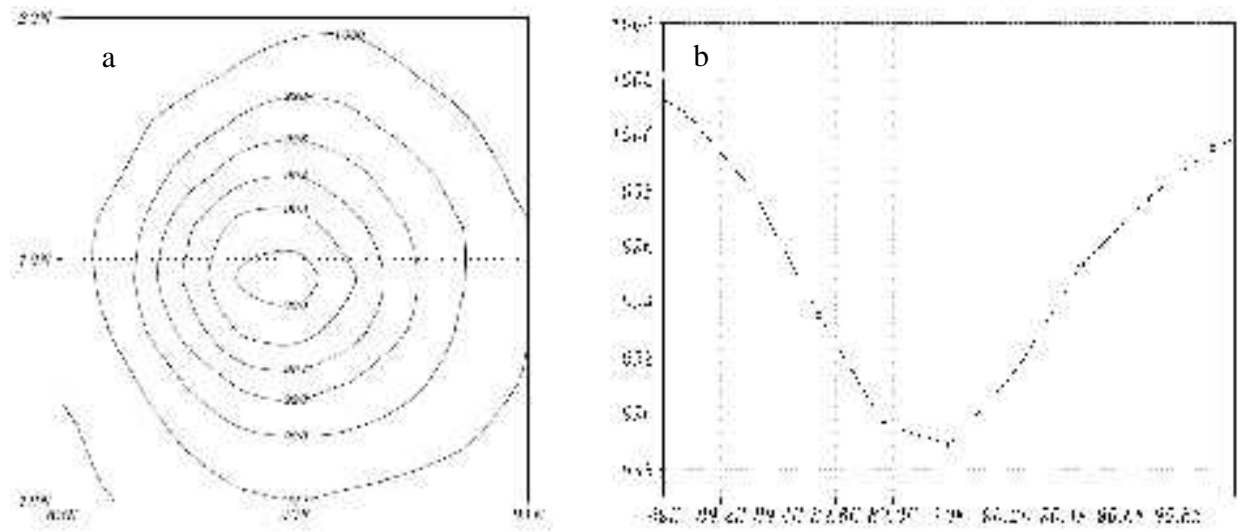

Fig. 2. (a) Distribution of model simulated MSLP (hPa) and (b) E-W sectional view of simulated MSLP at mature stage of cyclone Bijli at 0000 UTC of 18 April, 2009.

The distribution of surface wind of cyclone Bijli at 0000 UTC of 18 April, 2009 has been shown in Fig. 3(a). The figure shows that the wind field of the cyclone is highly asymmetric in the horizontal distribution. The figure also shows that the surface wind distribution is well organized indicating that it was a strong system. A strong wind band (wind speed $>30 \mathrm{~m} / \mathrm{s}$ ) is found at a distance of around $25 \mathrm{~km}$ in the south of the system centre $\left(18.9^{\circ} \mathrm{N}, 90^{\circ} \mathrm{E}\right)$ with elongation in east-west. It is noted that the strong wind is found in the south side of the system.
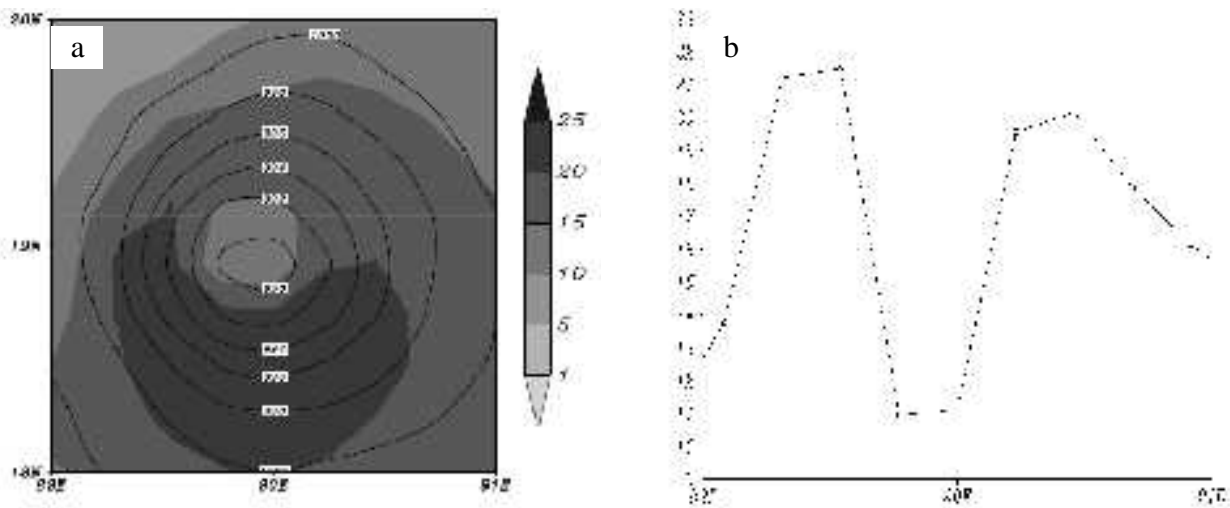

Fig. 3. (a) Distribution of model simulated surface wind (in left) and (b) north-south $(\mathrm{N}-\mathrm{S})$ sectional view of simulated surface wind (speed in $\mathrm{m} / \mathrm{s}$ ) at mature stage of cyclone Bijli at 0000 UTC of 18 April, 2009.

Fig. 3(b) shows the distribution of the surface wind of the cyclone Bijli along northsouth section passing through its centre $\left(18.9^{\circ} \mathrm{N}, 90^{\circ} \mathrm{E}\right)$. The figure demonstrates that a calm region is found at the eye of the system where wind speed is almost $10 \mathrm{~m} / \mathrm{s}$ and maximum wind is found in the eye wall at the left side of the system centre. 

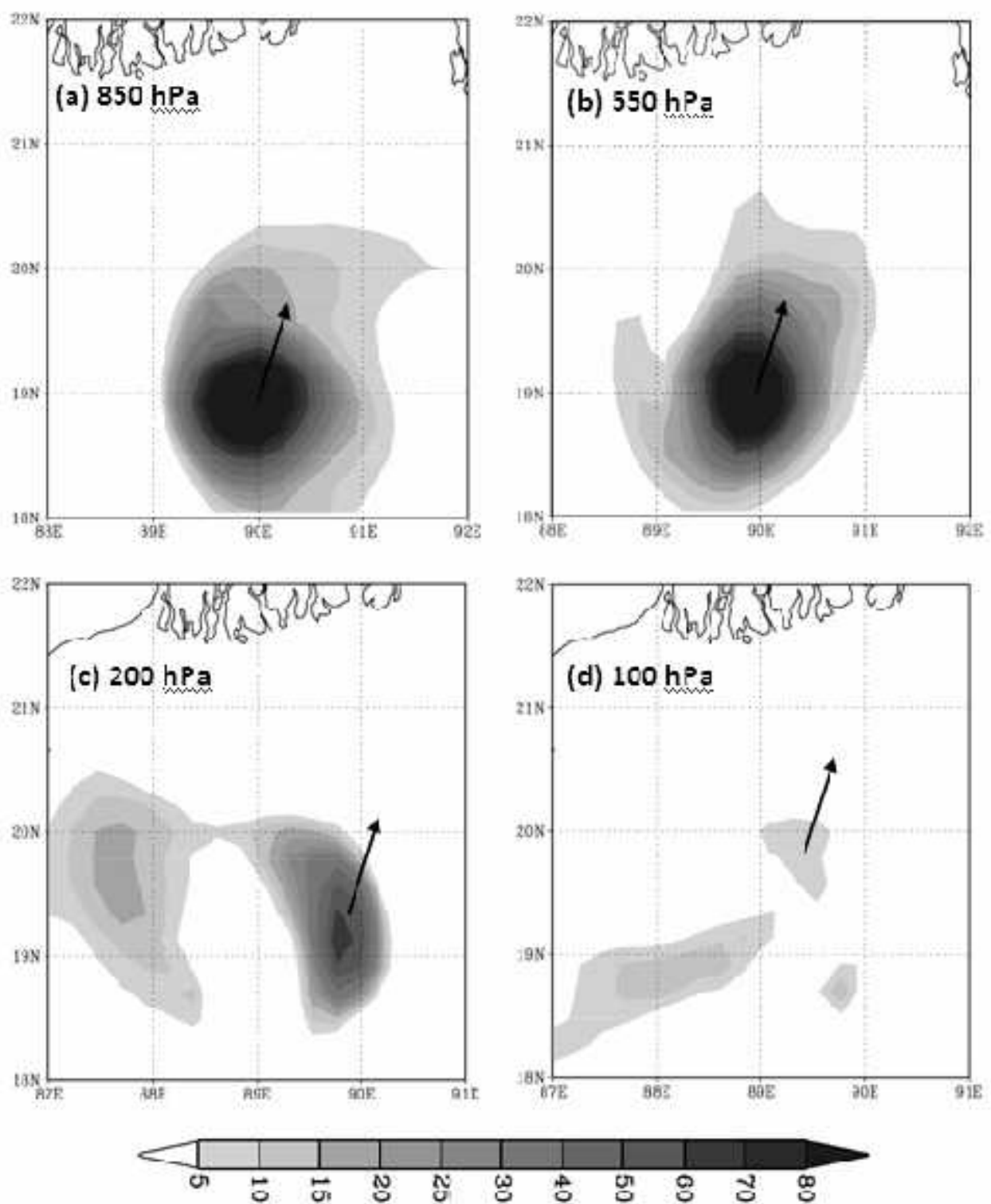

Fig. 4. Model simulated vorticity field at (a) $850 \mathrm{hPa}$, (b) $550 \mathrm{hPa}$, (c) $200 \mathrm{hPa}$, (d) 100 $\mathrm{hPa}$ level of cyclone Bijli at 0000 UTC of 18 April 2009 (Arrow indicates the simulated centre and direction of the system).

The horizontal distribution of the relative vorticity at 0000 UTC of 18 April, 2009 of cyclone Bijli at 850, 550, 200 and $100 \mathrm{hPa}$ levels has been shown in the Fig. 6(a-d). According to the Fig. 6(a), it is seen that the vorticity is distributed with maximum value in the centre $\left(18.9^{\circ} \mathrm{N} 90^{\circ} \mathrm{E}\right)$. The distribution maintains near circular pattern with some asymmetric features in the outer periphery. In 550 and $200 \mathrm{hPa}$, the strong vorticity is 
visible on the centre of the cyclonic system. In $100 \mathrm{hPa}$ level the weak vorticity is found at the centre.

To study the tracks of selected tropical cyclones the model was run for $24,48,72$ and $96 \mathrm{hrs}$ before the landfall time. Table 2 summarizes the predicted average translational speed of selected tropical cyclone Bijli (2009) along with the corresponding observed speed. The observed average translational speed is calculated for respective model forecast hour (24, 48, 72 and 96 hrs) and also for full observed track. Observed full track average implies that the average translational speed of the Bay of Bengal cyclone is about $14 \mathrm{~km} / \mathrm{hr}$. Fig. 5 shows the time variation of model simulated and observed six hourly average translational speeds of the above cyclones. Table 2 and Fig. 5 demonstrate that in general the translational speed of the system increases as it intensifies and moves towards landfall position.

Table 2. Average translational speed of selected tropical cyclones.

\begin{tabular}{lllll}
\hline $\begin{array}{l}\text { Initial date/ } \\
\text { time (UTC) }\end{array}$ & $\begin{array}{l}\text { Forecast } \\
\text { hours }\end{array}$ & $\begin{array}{l}\text { Simulated } \\
\text { average } \\
\text { translational } \\
\text { speed }(\mathrm{km} / \mathrm{hr})\end{array}$ & $\begin{array}{l}\text { Obs. translational } \\
\text { speed }(\mathrm{km} / \mathrm{hr}) \\
\text { [Respective forecast } \\
\text { hours average] }\end{array}$ & $\begin{array}{l}\text { Obs. translational } \\
\text { SPEED }(\mathrm{km} / \mathrm{hr})[\text { full } \\
\text { track average] }\end{array}$ \\
\hline 13 April/1800 & 96 & 8.10 & 13.85 & 13.85 \\
14 April/1800 & 72 & 14 & 16.45 & \\
15 April/1800 & 48 & 15.9 & 19.5 & 26.72 \\
\hline
\end{tabular}

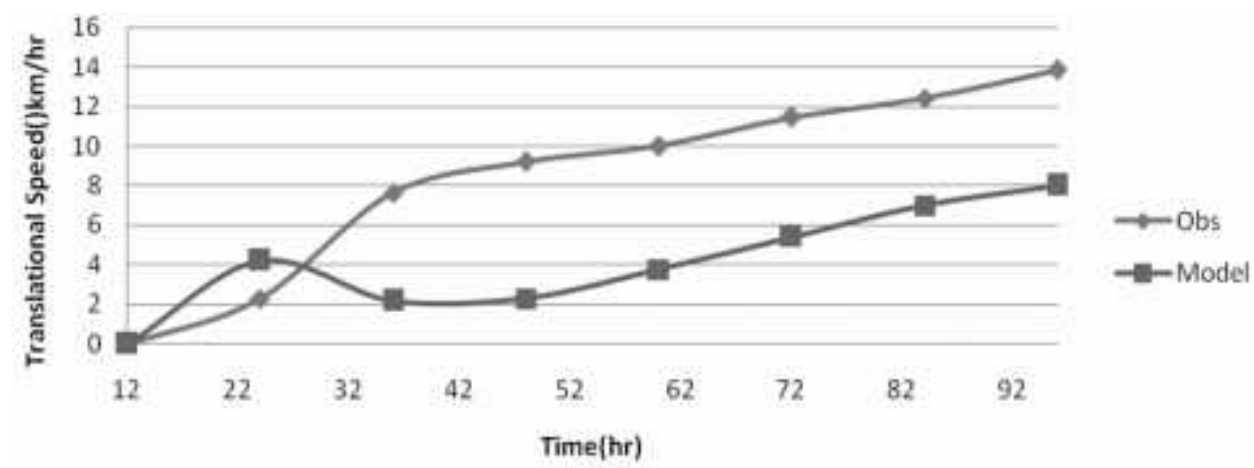

Fig. 5. Time variation of model simulated and observed 12 hourly average translational speed of cyclone Bijli beginning 1800 UTC of 13 April, 2009.

It is found from Table 2 that the simulated translational speed of Bijli is low compared with the actual speed of the system. Here $24 \mathrm{hrs}$ forecasts speed is slightly less than the observed. 

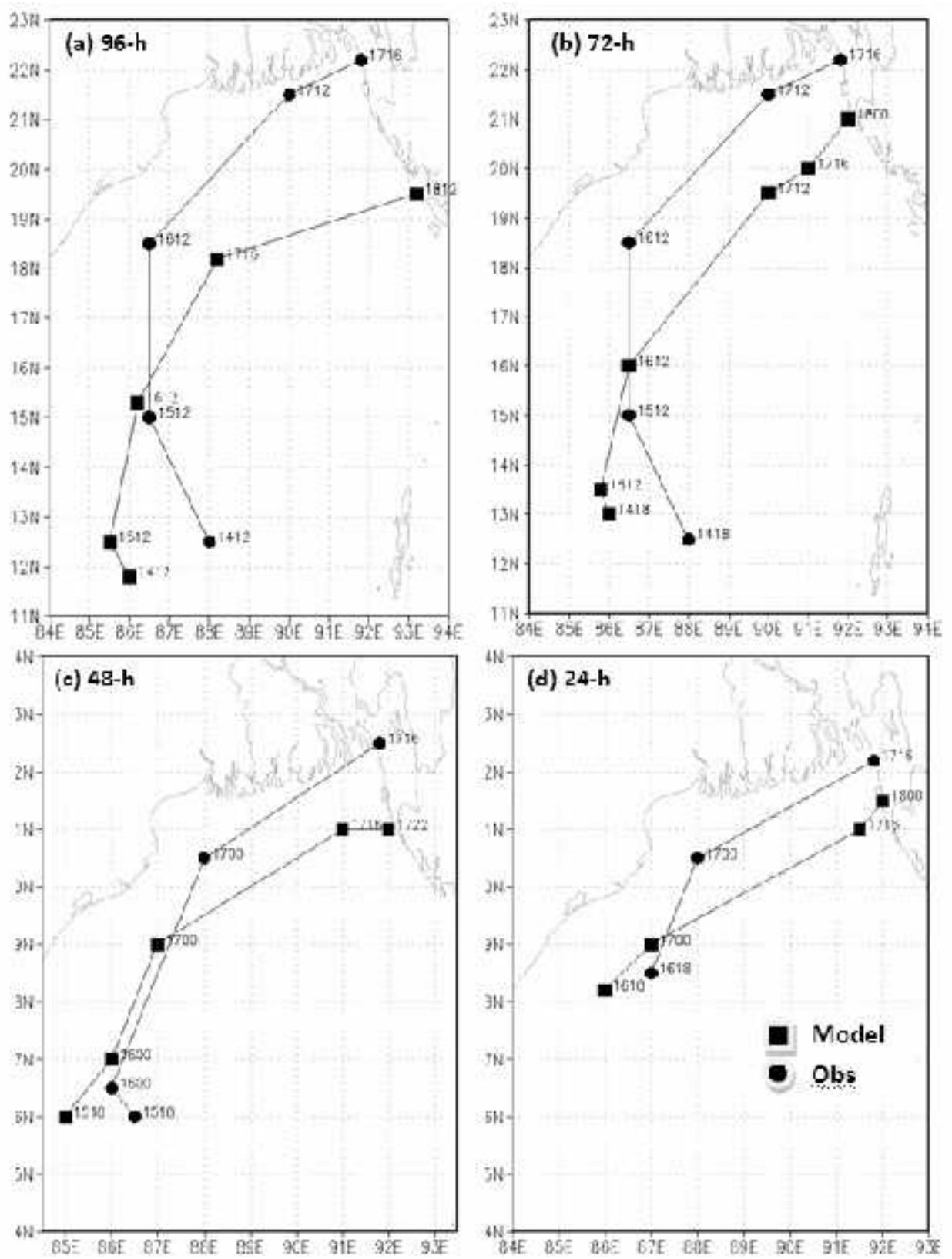

Fig. 6. Model simulated and observed track of cyclonic storm Bijli (2009), (a) $96 \mathrm{hrs}$ forecast beginning 1800 UTC, 13 April, (b) 72 hrs forecast beginning 1800 UTC, 14 April, (c) 48 hrs forecast beginning 1800 UTC, 15 April and (d) 24 hrs forecast beginning 1800 UTC, 16 April.

Fig. 6 (a-d) shows 96, 72, 48 and 24 hrs forecasts track of cyclone Bijli (2009) beginning from 1800 UTC of 13, 14, 15 and 16 April, respectively. It reveals that model was capable to capture north-eastward movement in this case. The 96 and $72 \mathrm{hrs}$ 
predicted track are almost same. Again 48 and 24 hrs are almost same but better than the previous two. It is found that the simulated landfall point of Bijli seems quite accurate with 48 and 24 hrs forecast based on 1800 UTC of 15 April and 16 April, respectively.

The model results produce an overall view that for weak system the predictions generate the direction of the motion very efficiently indicating the probable areas of the coast to be hit. However, the 24 and 48 hrs predictions show the better representation of the tracks, landfall position and landfall time.

As landfall of tropical cyclones is very important to the cyclone forecasters, the landfall position and time errors are investigated for evaluating the model performances. The results are presented in Table 3. It reveals that reducing the prediction hours with updated initial fields reduces the landfall errors. The tables show that most of the time the 24 and $48 \mathrm{hrs}$ predictions exhibit low landfall position errors whereas 72 and $96 \mathrm{hrs}$ predictions have comparatively high landfall position errors. There are variations in the landfall time errors. The $48 \mathrm{hrs}$ predictions show low landfall time errors than that of 24 , 72 and $96 \mathrm{hrs}$ predictions for the selected cyclone Bijli.

It appears from the above discussion that the ARW model has high potential to forecast position and time of landfall of the Bay of Bengal cyclones with the certain amount of uncertainty. However, further studies on sensitivity experiments with model resolution, boundary layer formulation, model physics and cumulus parameterization schemes on track prediction are required for proper tuning of the model to improve the prediction accuracy and reduce landfall error. Landfall point and time error during cyclonic storm Bijli are shown in Table 3.

Table 3. Landfall point and time error during cyclonic storm Bijli.

\begin{tabular}{|c|c|c|c|c|c|c|c|}
\hline \multirow{2}{*}{$\begin{array}{c}\text { Base date/ } \\
\text { time } \\
\text { (UTC) }\end{array}$} & \multirow{2}{*}{$\begin{array}{c}\text { Forecast } \\
\text { hours }\end{array}$} & \multicolumn{2}{|c|}{ Landfall forecast } & \multicolumn{2}{|c|}{ Actual landfall } & \multicolumn{2}{|l|}{ Error } \\
\hline & & $\begin{array}{l}\text { Position (Lat } \\
{ }^{0} \text { N/ Lon }{ }^{0} \mathrm{E} \text { ) }\end{array}$ & $\begin{array}{l}\text { Date/time( } \\
\text { UTC) }\end{array}$ & $\begin{array}{c}\text { Position }\left(\text { lat }{ }^{0} \mathrm{~N}\right. \\
\left.\text { / lon }{ }^{0} \mathrm{E}\right)\end{array}$ & $\begin{array}{l}\text { Date/time } \\
\text { (UTC) }\end{array}$ & $\begin{array}{c}\text { Difference of } \\
\text { landfall point }(\mathrm{km})\end{array}$ & $\begin{array}{l}\text { Time } \\
\text { (hrs) }\end{array}$ \\
\hline $13 / 1800$ & 96 & $19.5 / 93.2$ & $18 / 1200$ & $22.2 / 91.8$ & $17 / 1600$ & 337 & $20 \mathrm{D}$ \\
\hline $14 / 1800$ & 72 & $21 / 92$ & $18 / 0000$ & do & do & 135 & 08D \\
\hline $15 / 1800$ & 48 & $21 / 92.5$ & $17 / 2200$ & do & do & 154 & $06 \mathrm{D}$ \\
\hline $16 / 1800$ & 24 & $21.5 / 92$ & $18 / 0000$ & do & do & 80 & $08 \mathrm{D}$ \\
\hline
\end{tabular}

D indicates delay of actual landfall time.

\section{CONCLUSION}

From the above findings the following conclusions are drawn:

(i) The formation of the first low pressure system 30 - $36 \mathrm{hrs}$ ahead from its actual genesis without incorporation of any artificial vortex. It is also able to forecast the intensification of the system and is capable to predict the well-marked low 42 - $60 \mathrm{hrs}$ before the formation. The model is capable to forecast the formation 
of the first depression 60 - $78 \mathrm{hrs}$ in advance. This indicates the high and unique predictive power of ARW model for predicting the tropical cyclone formation.

(ii) The model generates a realistic structure of the tropical cyclones with high spatial details without use of any idealized vortex in the initial. This has been possible due to the higher spatial resolution of the regional model.

(iii) One of the important findings of the study is that the model has successfully predicted the tracks, recurvature and probable areas and time of landfall of the selected tropical cyclone Bijli with high accuracy even in the $72 \mathrm{hrs}$ predictions.

The Bay of Bengal is a data sparse region, improvement of the meteorological network through deployment of fixed and floating data collection buoys over the Bay of Bengal will improve the initial field and thus the performance of the model will also improve.

\section{ACKNOWLEDGEMENTS}

The authors are thankful to NCAR for providing the WRF model code and NCEP for the initial and lateral boundary condition data. Thanks are due to IMD, BMD and SMRC for providing necessary data and computer facility to carry out the study.

\section{REFERENCES}

Chen, S. H. 2007. The impact of assimilating SSM/I and Quik-SCAT satellite winds on Hurricane Isodore simulation, Monthly Weather Review 135: 549-566.

Davis, C. A., W. Wang, S. Chen, Y. Chen, K. Corbosiero, M. DeMaria, J. Dudhia, G. Holland, J. Klemp, J. Michalakes, H. Reeves, R. Rotunno and Xiao, Q. 2008. Prediction of landfalling hurricanes with the advanced hurricane WRF model. Monthly J. Weather Review 136: 19902005.

Gupta, A. 2006. Current status of tropical cyclone track prediction techniques and forecast errors, Mausam 57: 151-158.

Hong, S. Y. and J. W. Lee. 2009. Assessment of the WRF model in producing a flash-flood heavy rainfall event over Korea, Atmos. Res. 93: 818-831.

Lee, C. S., R. Edson and W. M. Gray. 1989. Some Large-scale characteristics associated with tropical cyclone development in the North Indian Ocean during FGGE:, Monthly Weather Review 117: 407-426.

Mohanty, U. C. and A. Gupta. 1997. Deterministic methods for prediction of tropical cyclone tracks. Mausam 48: 257-272.

Mohanty, U. C., K. K. Osuri, A. Routray, M. Mohapatra and S. Pattanayak. 2010. Simulation of Bay of Bengal tropical cyclones with WRF model: impact of initial and boundary conditions. Mar. Geodesy 33: 294-314.

Niyogi, D., T. Holt, S. Zhong, P. C. Pyle and J. Basara. 2006. Urban and land surface effects on the 30 July 2003 mesoscale convective system event observer in the Southern Great Plains. J. Geophysical Res. 111: D19107, doi: 10.1029/ 2005JD006746.

Osuri, K. K., U. C. Mohanty, A. Routray, A. K. Makarand and M. Mohapatra. 2012a. Sensitivity of physical parameterization schemes of WRF model for the simulation of Indian seas tropical cyclones. Natural Hazards 63: 1337-1359. 
Osuri, K. K., U. C. Mohanty, A. Routray and M. Mohapatra. 2012b. Impact of Satellite Derived Wind Data Assimilation on track, intensity and structure of tropical cyclones over North Indian Ocean. Internat. J. Remote Sensing 33: 1627- 1652.

Pattanaik, D. R. and Y. V. Rama Rao. 2009. Track prediction of very severe cyclone 'Nargis' using high resolution weather research forecasting (WRF) model. J. Earth Syst. Sci. 118: 308-329.

Pattanayak, S. and U. C. Mohanty. 2008. A comparative study on performance of MM5 and WRF models in simulation of tropical cyclones over Indian seas. Curr. Sci. 95: 7, 923-936.

Pu, Z., Xuanli. Li, C. S. Velden, S. D. Aberson and W. T. Liu. 2008. The impact of aircraft Dropsonde and Satellite wind data on numerical simulations of two landfalling tropical cyclone storms during the tropical cloud systems and processes experiment. Weather and Forecasting 23: 62-79.

Routray, A., U. C. Mohanty, Dev. Niyogi, S. R. H. Rizvi and Krishna K. Osuri. 2010. Simulation of heavy rainfall events over Indian monsoon region using WRF-3DVAR Data Assimilation System. Meteorology and Atmospheric Physics 106: 107-125.

Velden, C. S., T. L. Olander and S. Wangzong. 1998. The impact of multispectral GOES-8 wind information on Atlantic tropical cyclone track forecasts in 1995. Part-I: dataset methodology, description, and case analysis. Monthly Weather Review 126: 1202-1218.

(Revised manuscript received on 30 June, 2015) 